\title{
Eosinophil Count
}

National Cancer Institute

\section{Source}

National Cancer Institute. Eosinophil Count. NCI Thesaurus. Code C64550.

The determination of the number of eosinophils in a blood sample. 